\title{
Professor Andrzej Sawicki 1947 - 2016
}

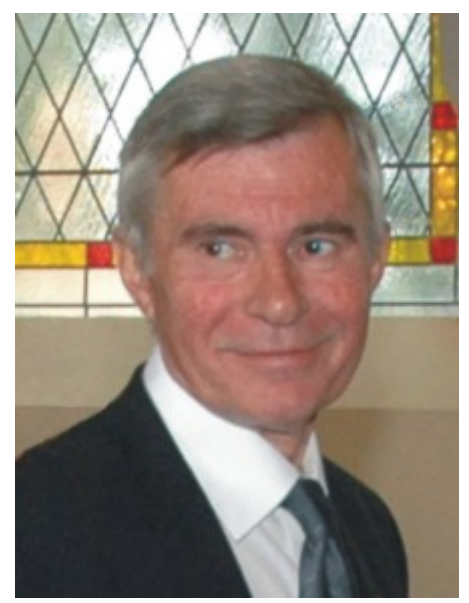

Professor Andrzej Sawicki, a distinguished Polish scientist, died on 5 March 2016 at the age of 68 . He made outstanding contributions to several branches of civil engineering, soil mechanics and applied mechanics, including structural mechanics, hydro-elasticity, theory of composite materials, mechanics of reinforced soil, mechanics of sand compaction and liquefaction. The fields of soil mechanics and applied mechanics have lost in him an eminent and very creative researcher.

\section{Scientific career}

Andrzej Sawicki was born on 31 August 1947 in Bydgoszcz, Poland. For most of his life and career he was based in Gdańsk. In 1970 he graduated from the Gdańsk University of Technology (GUT) with an MSc degree in civil engineering. In 1971 he started to work as a research assistant at the Department of Structural Mechanics of the GUT, where he completed the doctoral thesis The dynamics of floating roofs treated as the problem of hydro-elasticity under the supervision of Prof. Piotr Wilde, and in 1974 was awarded a PhD degree in structural mechanics. In 1977 he moved to the Institute of Hydro-Engineering of the Polish Academy of Sciences in Gdańsk (IBW PAN), where, except for a few years abroad, he worked until his death. In 1981 he obtained a DSc degree (habilitation) for the thesis Continuum theory of composite materials and its application to the analysis of reinforced soil. In the years 1981-1984 and 1989-1990 Andrzej Sawicki worked at the School of Mathematics of the University of East Anglia in Norwich, UK, and in 1990-1991 he was at the School of Civil 
Engineering of the University of Birmingham, UK. In 1989 the President of the Republic of Poland awarded him the state title of Professor. He was the Director of the IBW PAN for nearly 18 years: in 1991-1997 (for two terms) and in 2004-2016 (for nearly three terms). For about four decades Prof. Sawicki was the Head of the Department of Geomechanics of the IBW PAN. He supervised six PhD theses, advised three DSc theses, and assisted many junior scientists with inspiration and constructive help. For eight years, between 1993 and 2001, he served as the Chief-Editor of the quarterly journal Archives of Hydro-Engineering and Environmental Mechanics (AHEM), and until his untimely departure was a member of its Editorial Board.

\section{Research}

Professor Sawicki was active in many research fields. Throughout his career he was a very prolific writer and authored or co-authored well over 200 research papers, 12 books and dozens of other edited works and publications. His first research interests were focused on structural mechanics and hydro-elasticity. Soon he developed interests in continuum and applied mechanics, and used their methods for solving a wide range of problems of importance to civil engineering; in the first place to soil mechanics and geomechanics. In hindsight, it appears that his most significant and lasting contributions were made to two disciplines: the mechanics of reinforced soil and the mechanics of sand compaction and liquefaction.

Prof. Sawicki started his research on the problems of the mechanics of reinforced soil in the mid-1970s. By applying the methods of the mechanics of composite materials, he developed a number of constitutive models describing the behaviour of reinforced soil in the elastic, visco-elastic, elasto-plastic and rigid-plastic regimes. He then employed these models for the analysis of the bearing capacity and limit states of reinforced soil structures and for the solution of a wide range of civil engineering problems. Prof. Sawicki was active in this area for about 25 years and published numerous papers on this subject. The most important results were summarized in his book Mechanics of Reinforced Soil (Balkema, Rotterdam) published in 2000, which is among the first books on this topic in the world literature.

Prof. Sawicki's other major field of research was the mechanics of water-saturated soils, with a particular focus on the theoretical description of compaction, pressure generation and liquefaction phenomena in saturated sands under monotonic and cyclic loadings. He began the research in this area in the early 1980s in close collaboration with Prof. Leslie Morland from the University of East Anglia in Norwich, when they developed their first models for fluid-saturated granular media. From the mid-1980s, however, for three decades, he worked in this field together with his colleagues from the Institute of Hydro-Engineering in Gdańsk. The results of this research effort were published in dozens of papers devoted to laboratory, theoretical and numerical aspects of the dynamic behaviour of saturated soils, including the dynamic soil-structure interaction problems and the modelling of wave propagation phenomena in saturated 
sands. Many results concerning the soil liquefaction mechanism and its modelling are presented in his book The Puzzle of Soil Liquefaction (IBW PAN Publishing House, Gdańsk) published in 2014.

Besides the above two research fields, Prof. Sawicki also made many contributions to other branches of geomechanics and geotechnics. His most important results include the analysis of groundwater flows in coastal zones, the development of a model for fly-ash composites, the formulation of constitutive models describing the rheology of geosynthetic materials, the analysis of earth structure stability, and the development of a model for the problem of extrication of large objects from the seabed.

\section{Honours}

As an expression of high regard for the scientific achievements of Prof. Sawicki, he received a number of Polish state awards. In 1995 and 2003 he was awarded, respectively, the Officer's and the Knight's Cross of the Order of Polonia Restituta, and in 1998 he obtained the Silver Cross of Merit. He received the Polish Prime Minister's award for outstanding scientific achievements in 2000, and his book Mechanics of Reinforced Soil was awarded by the Minister of Internal Affairs and Administration in 2000 and by the Minister of Infrastructure in 2002.

This special issue of Archives of Hydro-Engineering and Environmental Mechanics is devoted to the memory of Prof. Andrzej Sawicki and contains research papers written by his colleagues and co-workers from the Institute of Hydro-Engineering in Gdańsk, for whom he was a true Teacher and Master, and by whom he is greatly missed.

Ryszard Staroszczyk Co-Editor of AHEM 